\title{
Design and Development of Shunt Active Filter Using MATLAB for Minimization of Harmonics
}

\author{
Ravi Samikannu ${ }^{1 *}$, R.Rohini ${ }^{2}$, V.Sampath Kumar ${ }^{3}$, Vitaliy Mezhuyev ${ }^{4}$ \\ ${ }^{1}$ Botswana International University of Science and Technology, Palapye, Botswana \\ ${ }^{2}$ Vivekanandha College of Engineering for Women, Namakkal, India \\ ${ }^{3}$ Amity University, India \\ ${ }^{4}$ University of Malaysia Pahang, Pahang, Malaysia \\ *Corresponding authorE-mail:ravis@biust.ac.bw
}

\begin{abstract}
Nonlinear loads draw non sinusoidal current and voltage from the utility. These non-sinusoidal current and voltages created due to nonlinear loads are called harmonics. The harmonic voltage and current disturbs the system back and creates big power quality problem. Therefore in order to mitigate harmonic problems different mechanisms are used. In this work as introduction different power quality problems, harmonics and their mitigation techniques/filters are presented and discussed. Between the different ways to minimize/eliminate harmonics active power filters are most Prominent one. This research work presents three phase system shunt active power filter working based on PQ theory. MATLAB simulation used and results are discussed.
\end{abstract}

\section{Introduction}

\subsection{Power Quality}

The distortion of voltage, current and power waveform is called power quality problem in power system. In recent years, the developments of power electronics components have great advantage in energy conversion and utilization. Power electronics equipment draws distorted current from the system. As the current distortion is conducted through transmission line, it creates voltage distortion in various parts of the power system. Voltage distortion increases because of current distortion has become a major problem for the utilities at distribution and transmission levels. Line losses and losses in electrical equipment's connected in the transmission system are increased due to the high harmonic or distortion current flowing through system [1-2].

The harmonics are caused by non-linear loads such as, arc furnaces, switch mode power supply, fluorescent lamps, rectifiers etc. As a result of these non-linear loads the supply system lead to overheating of cables and conductors, electromagnetic interference to nearby communication facilities etc. By considering the effects of harmonics in various equipment's in power system, it is necessary to eliminate these harmonics.

Traditionally, passive filter and capacitor bank are used to filter the harmonics and compensate the reactive current components due to non-linear loads. They are simple control but very complex under resonant conditions. When the supply voltage waveforms are non-sinusoidal, the problems with passive filters are more pronounced due to the possibility of filter overloading and resonance. The conventional filters have some disadvantages such as the fixed compensation, large size and resonance. To overcome these problems active filters are introduced. The filter is working for different functions like harmonic filtering, reducing damping, providing isolation, load balancing. Additionally it is performing the reactive-power control to achieve power-factor improvement and voltage regulation, reducing the voltage-flicker. Advanced active filters well advanced in filtering performance with the smaller in physical size. The advanced filters are flexible in application while it is compared to traditional passive filters using inductors and capacitors [3-6].

\subsection{Statement of the Problem}

In earlier days, the harmonic problem in power system created by magnetic saturation of transformers, and because of industrial loads like arc furnace, arc welding machine. The major concerns were the effect of harmonics mainly in the induction and synchronous machines. Today, however, additional methods for dealing with harmonics are necessary for the following reasons

- Nonlinear loads grow exponentially in recent years in industrial, commercial and residential areas.

- The changes in the increase in the Network resonances.

- Generally the power system equipment's and the system loads are sensitive to the harmonics.

Objective of this study is reducing harmonic distortion, improving system capacity and reliability, energy efficiency using active harmonic filter. The industry chosen for the data collection is METEC (Hibret manufacturing and tool engineering industry, Ethiopia). The specific objective is reducing the harmonic distortion and improving the energy efficiency. 


\section{Industry Data Collection and Analysis}

\subsection{Data Collection}

Hibret manufacturing and tool engineering industry receives $15 \mathrm{KV}$ power from utility by three $15 \mathrm{KV} / 410 \mathrm{~V}$ transformers and it fed to small furnace shop, welding shop and for general services. The Microvip3 plus power and harmonic analyzer measured all necessary data's single phase and three phase of voltage, current, active power, reactive power, apparent power, power factor, THD. The measured values of Single phase $\&$ three phases Voltage, current, active, reactive \&apparent power is shown in Fig.1. The THD of L1, L2and L3 for PCC1 is shown in Fig.2. Waveform of voltage and current is shown in Fig.3, Fig.4 and Fig.5. The total harmonic distortion analysis is shown in Fig.6, Fig.7 and Fig.8.

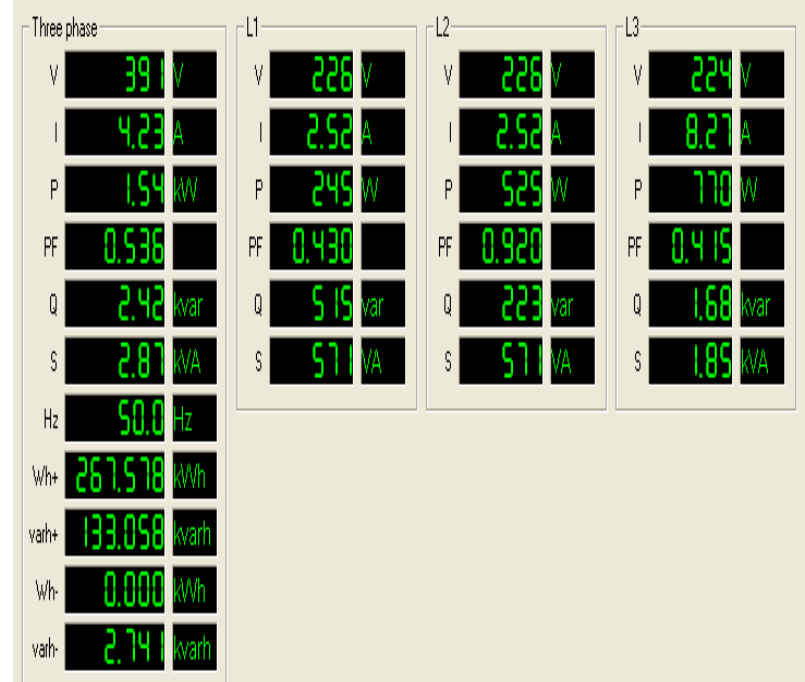

Fig.1: Single phase \& three phase system Voltage, current,active, reactive \&apparent power for PCC1

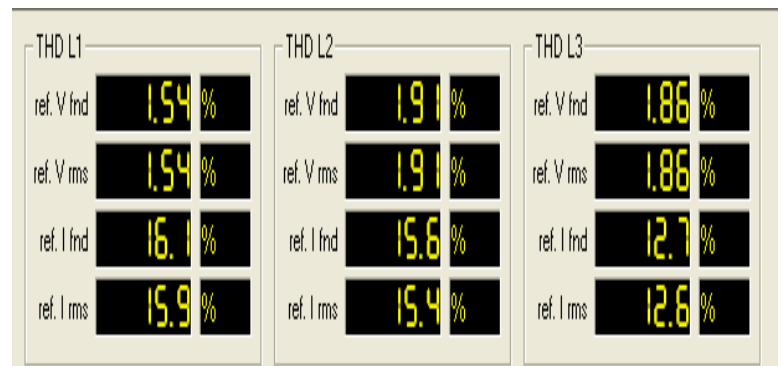

Fig.2: THD of L1, L2and L3 for PCC1

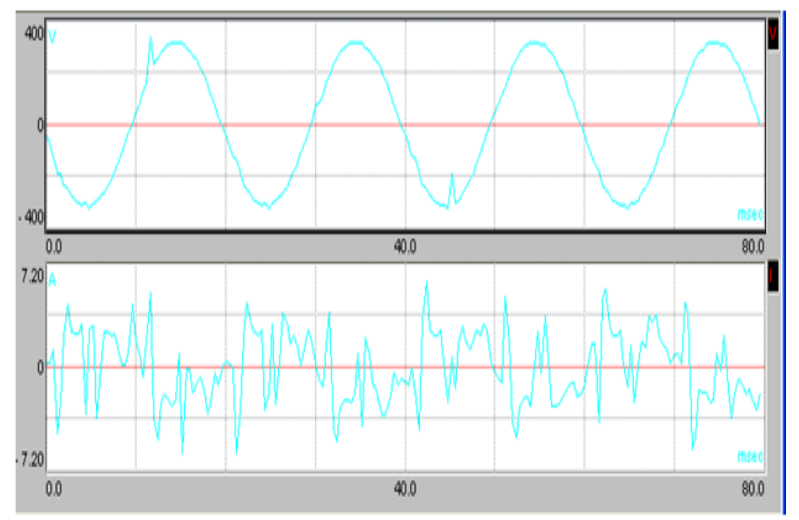

Fig.3: Waveform of voltage and current of L1 for PCC 1

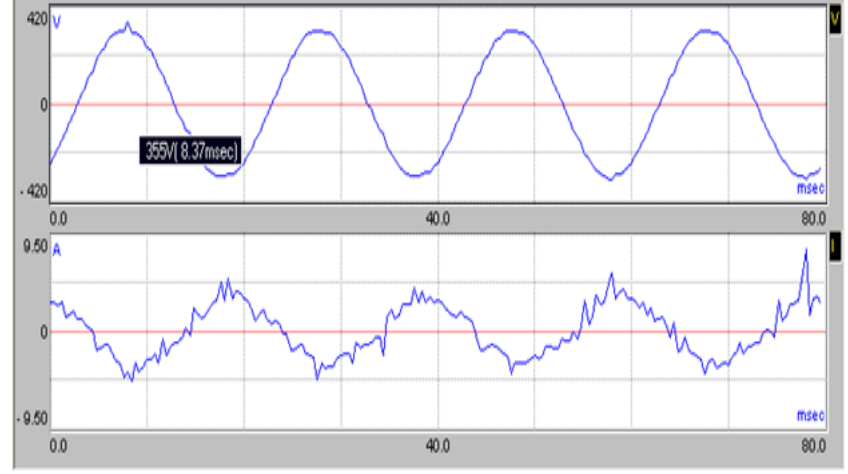

Fig.4: Waveform of voltage and current of L2 for PCC 1

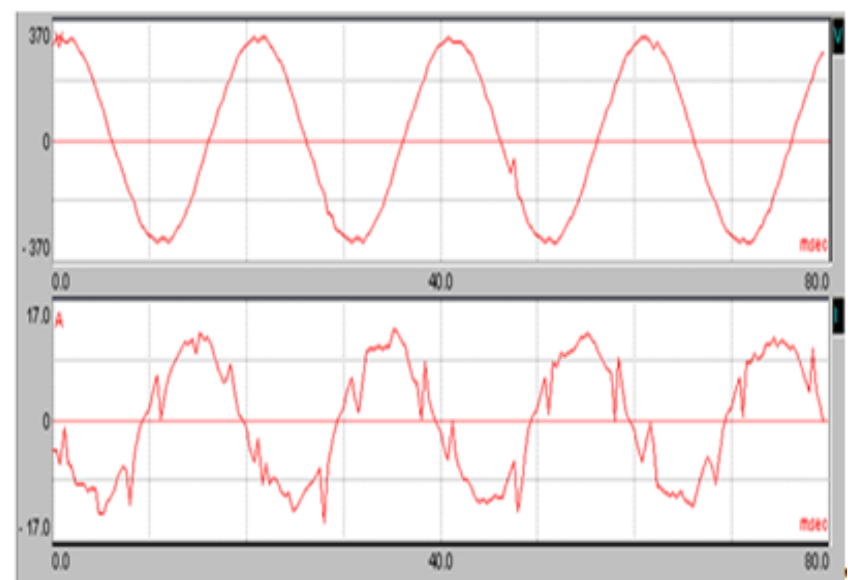

Fig.5: Waveform of voltage and current of L3 for PCC 1

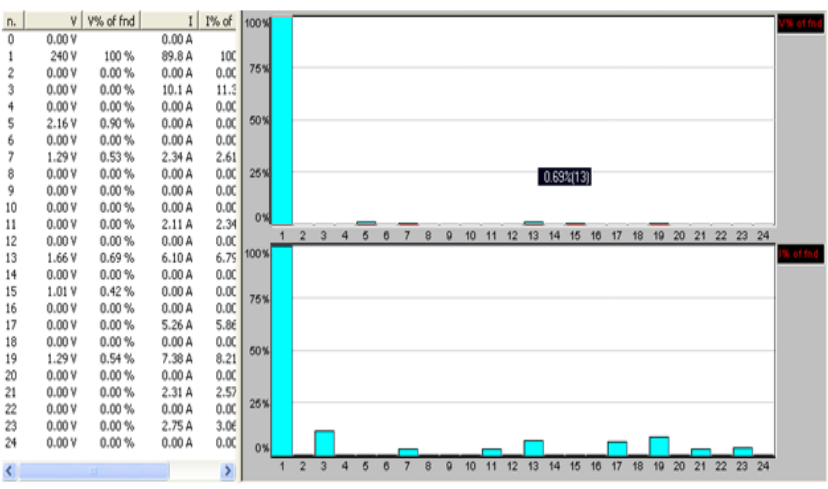

Fig.6: THD L1 for PCC1

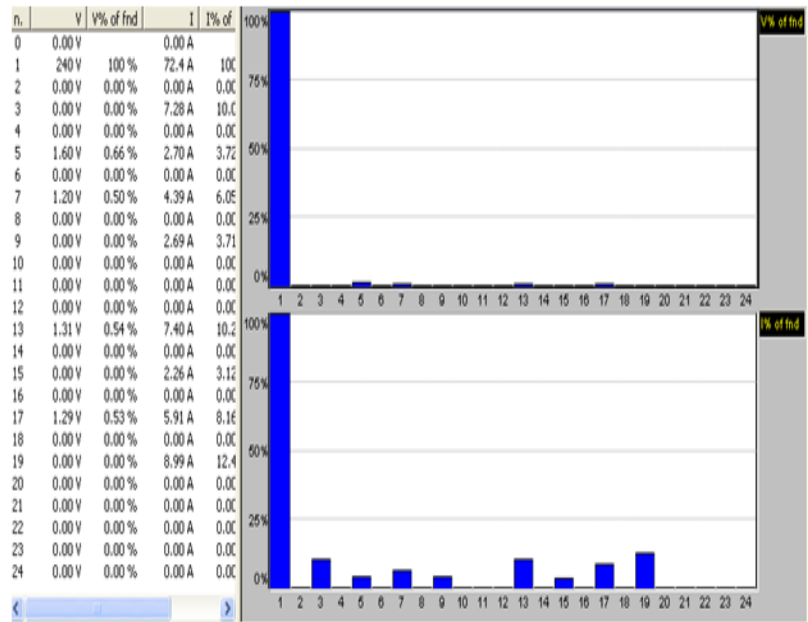

Fig.7: THD L2 for PCC1 


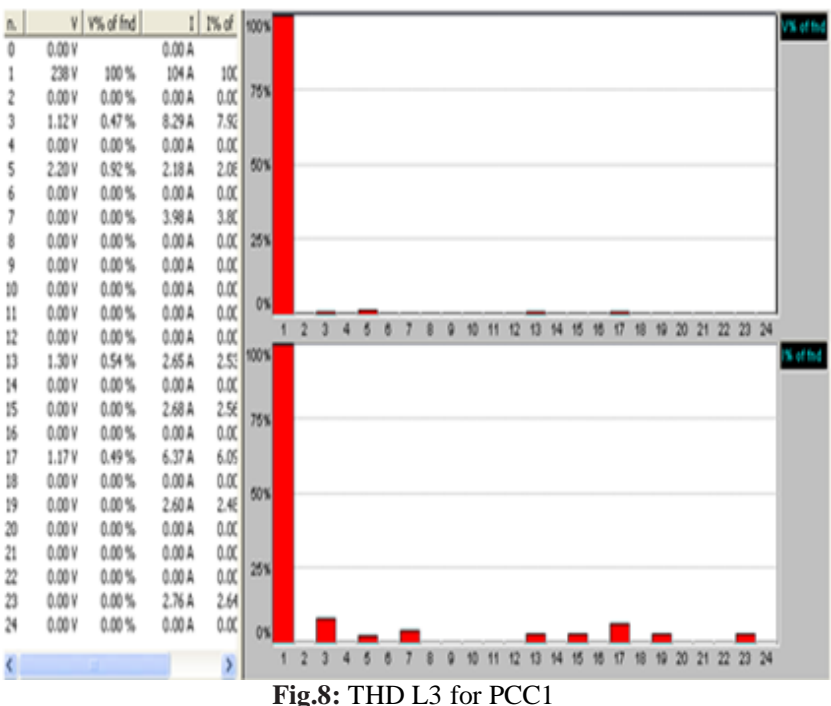

In a power system all the different equipment they are not with similar ratings they have different ratings. Calculations are used to be performed as because the different components and the units are rated in different format. The percentage values given in the nameplates calculated with the respect to the nameplate values given. That's the reason the common base KVA or MVA and also a base KV is used. The second one is based on the total capacity of a plant or system for base MVA or KVA. The Table. 1 shows the name plate data of transformer. Table. 2 and Table. 3 shows the current and voltage comparison with the standard values.

Table 1: Name Plate Data of the Transformer

\begin{tabular}{|l|l|l|l|l|l|}
\hline Apparent Power (kVA) & $\begin{array}{l}\mathrm{V}_{1} \\
(\mathrm{kv})\end{array}$ & $\begin{array}{l}\mathrm{V}_{2} \\
(\mathrm{~V})\end{array}$ & $\begin{array}{l}\mathrm{I}_{1} \\
(\mathrm{~A})\end{array}$ & $\begin{array}{l}\mathrm{I}_{2} \\
(\mathrm{~A})\end{array}$ & $\begin{array}{l}\mathrm{P}_{\mathrm{L}} \\
(\mathrm{W})\end{array}$ \\
\hline 630 & 15 & 410 & 30.2 & 900 & 1500 \\
\hline
\end{tabular}

$\mathrm{I}_{\mathrm{b}}=$ Base current in Amps $=\frac{M V A_{b} x 10^{3}}{\sqrt{3} k V_{b}} A m p s$

Percentage reactance,

$\% X=\frac{I X}{V} x 100$

Where, I=full load current (transformer rating at secondary side)

Phase voltage is mentioned as $\mathrm{V}$, reactance in ohms/ Phase is $\mathrm{X}$ and the short circuit current expressed as,

$I_{S C}=\frac{I * 100}{\% X}$

(or)

$I S C=\frac{1000 \cdot M V A_{S C}}{\sqrt{3} \cdot K V}$

$\mathrm{I}_{\mathrm{sc}}=$ Short Circuit current at PCC

Short Circuit KVA = Base KVA x $\frac{100}{\% X}$

or

Short circuit MVA $=\sqrt{3} K V_{l} I_{s c}$

Where, $\mathrm{I}_{\mathrm{SC}}$ is in KA

Where, Base KVA is KVA rating of a single transformer.

Percentage reactance can be expressed in terms of KVA and KV as, $\% X=\frac{X . K V A}{10(K V)^{2}}$

The ohmic values of $\mathrm{R}, \mathrm{X}$, and $\mathrm{Z}$ value of the transformer are
$\mathrm{Z}_{\mathrm{s}}=$ System impedance $=\frac{M V A_{b}}{M V A_{s c}} p \cdot u$

S.C. Ratio $=$ Short circuit Ratio $=\frac{I_{S C}}{I_{L}}$

Where $\mathrm{I}_{\mathrm{sc}}$ is the short-circuit current at the PCC $\mathrm{I}_{\text {load }}$ is load current at PCC

At bus-bar1 (PCC 1),

$\mathrm{I}_{\mathrm{sc}} / \mathrm{I}_{\mathrm{load}}$

Isc $=\frac{\text { Full load current of KVA transformer }}{Z(\text { impedance }) \text { of KVA transformer }}$

$I_{\text {load }}=900 \mathrm{~A}$ (transformer rating at secondary side)

$\mathrm{Z}$ (impedance) of $630 \mathrm{KVA}=6 \%$

Isc $=\frac{\text { Iload }}{\mathrm{Z}(\text { impedance) } \mathrm{ofKVA} \text { transformer }}=\frac{900}{0.06}=15000 \mathrm{~A}$

$\frac{\text { Isc }}{\text { Iload }}=\frac{15000}{900}=16.67$

Table 2:Current Comparison with the standard values

\begin{tabular}{|l|l|l|l|l|l|}
\hline \multirow{2}{*}{$\begin{array}{l}\text { Panel } \\
\text { name }\end{array}$} & \multicolumn{2}{|c|}{$\begin{array}{l}\text { Current distortion } \\
\text { limits IEEE 519 }\end{array}$} & \multicolumn{2}{|l|}{$\begin{array}{l}\text { Calculation and direct } \\
\text { measurement }\end{array}$} & Remark \\
\cline { 2 - 5 } & $\mathrm{I}_{\text {sc }} \mathrm{I}_{\text {load }}$ & TDD\% & $\mathrm{I}_{\text {sc }} / \mathrm{I}_{\text {load }}$ & TDD\% & \\
\hline $\begin{array}{l}\text { bus- } \\
\text { bar1 } \\
\text { (PCC 1) }\end{array}$ & $<20$ & 5.0 & 16.667 & 14.6 & $\begin{array}{l}\text { Requires } \\
\text { mitigation }\end{array}$ \\
\hline
\end{tabular}

Table 3: Voltage Comparison with the standard values

\begin{tabular}{|l|l|l|l|l|l|}
\hline \multirow{2}{*}{$\begin{array}{l}\text { Panel } \\
\text { name }\end{array}$} & \multicolumn{2}{|l|}{$\begin{array}{l}\text { Voltage distortion } \\
\text { limits IEEE 519 }\end{array}$} & \multicolumn{2}{|l|}{ direct measurement } & Remark \\
\cline { 2 - 4 } & $\begin{array}{l}\text { Bus } \\
\text { Voltage }\end{array}$ & TDD\% & $\begin{array}{l}\text { Bus } \\
\text { Voltage } \\
\mathrm{kV}\end{array}$ & TDD\% & \\
\hline $\begin{array}{l}\text { bus-bar1 } \\
\text { (PCC 1) }\end{array}$ & $<69$ & 5.0 & 0.41 & 1.7 & $\begin{array}{l}\text { Not Requires } \\
\text { mitigation }\end{array}$ \\
\hline
\end{tabular}

\section{Proposed System}

\subsection{Shunt Active Power Filter}

The Shunt Active Power Filter (SAPF) used to eliminate the harmonic currents. The Active Power Filter (APF) consists of DC bus capacitor with Voltage Source Inverter with the controlling device and inductors. Acting as the current source device and compensating the harmonic current at different nonlinear load conditions. APF is working in the way by generating the compensating current equal in the magnitude and opposite to the harmonic produced in the system. This compensation current can eliminate the harmonics. The VSI switches control the shape of the current. IGBT device is used for the inverter circuit as it is with high switching frequency. Triggering the inverter circuit depend on the control circuit system output. P-Q theory is to derive the compensating signal. The real and reactive power $\mathrm{p}$ and $\mathrm{q}$ gives the compensating current for the nonlinear load. The active power filtering is to compensating the harmonic currents which is occurred because of non-linear loads and make sure for producing the sinusoidal form of source currents and voltages. The Fig.9 shows the grid system with shunt active filter. The MATLAB simulation for the internal circuit of the shunt active filter is shown in Fig. 10. 


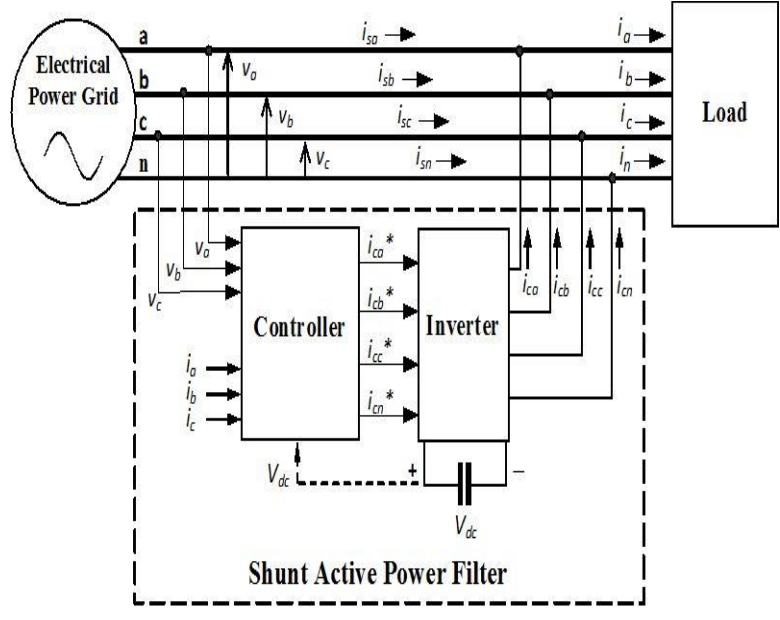

Fig.9: Grid system with shunt active filter

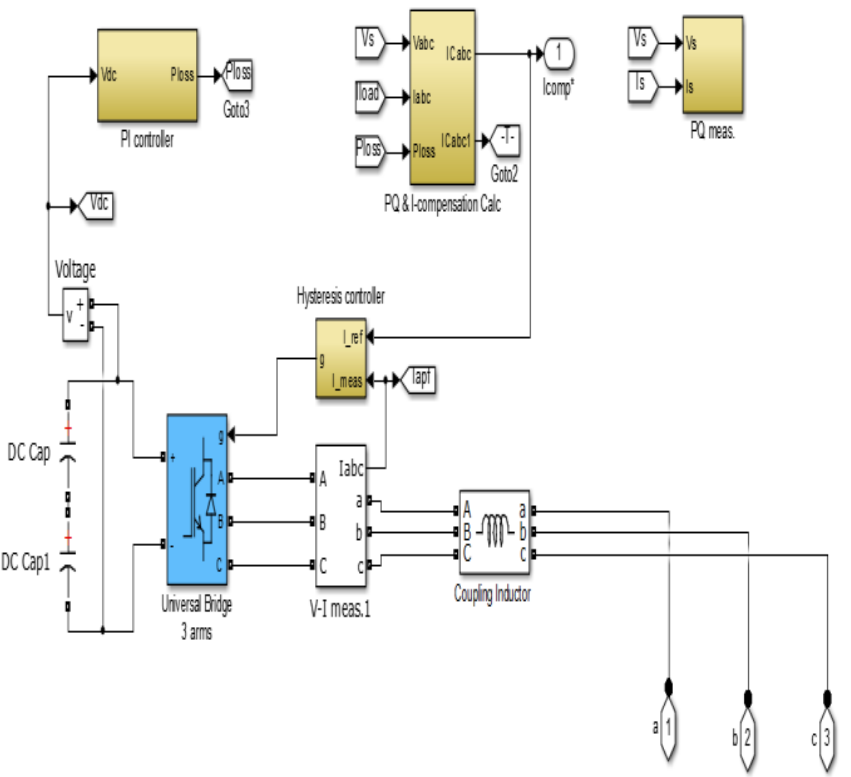

Fig.10: Internal circuit of shunt active filter

\subsection{Harmonic Current Extraction Methods}

In the active filtering the harmonic currents extraction is to be injected into the harmonic producing load. The best extraction of harmonics can be achieved by the efficient power filtering. Based on the compensating commands by frequency and time domain techniques the control methods are used. The Fast Fourier Transform (FFT) in the frequency domain is used to extract the current harmonics. The time domain methods having a faster response and it is requiring less calculation with the less memory use also. Among control methods in time domain, Instantaneous power $(\mathrm{p}-\mathrm{q})$ theory is one and presented in this work. The $\mathrm{p}-\mathrm{q}$ theory calculations are carried out in the shunt active power filter. From phase voltages $\left(\mathrm{v}_{\mathrm{a}}, \mathrm{v}_{\mathrm{b}}, \mathrm{v}_{\mathrm{c}}\right)$, and load currents $\left(\mathrm{i}_{\mathrm{a}}, \mathrm{i}_{\mathrm{b}}, \mathrm{i}_{\mathrm{c}}\right)$ and DC voltage, the controller calculates the reference currents, The inverter circuit uses reference currents to produce the compensation currents. The Fig.11 shows the model calculation of P-Q theory component. The Fig.12 shows the shunt active filter MATLAB simulation
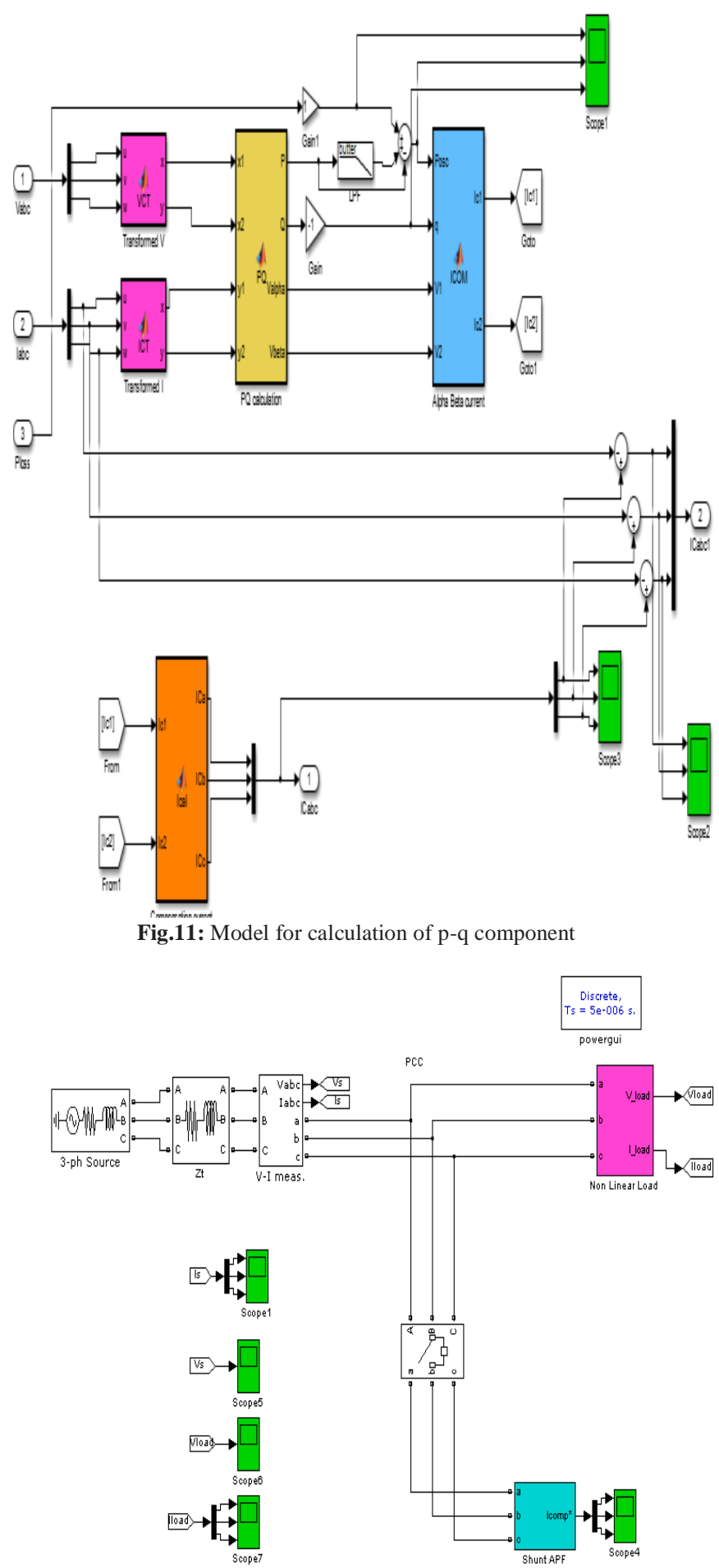

Fig.12: Shunt active power filter

\section{Simulation Results and Discussion}

From this assessment the harmonic disturbance is identified that it is a big power problem and causes conductor Overheating, reduces life time of capacitors false or spurious operations and trips of fuses and circuit breakers, increases iron and copper losses or eddy currents in transformer, , resulting in higher billings to consumers. Therefore to solve this problem shunt active filter is designed and simulation has been done. To see the improvement and compare the previous value with improved one we can see the results. Based on this before shunt active filter connected to the system the simulation showed that the THD of current is $17.17 \%$ and this is much greater than $5 \%$ the allowable standard by IEEE. This affects the power system and the machines in the 
industry so has to be mitigated. Based on this shunt active filter is designed and connected to the modelled system. It shows very good result in MATLAB simulation. The THD of current have been reduced from $17.76 \%$ to $3.7 \%$ which is below the allowable $5 \%$ stated by IEEE. The Fig.13 and Fig.14 shows the Total Harmonic Distortion results before the connection of filter circuit and after the connection of Filter circuit.

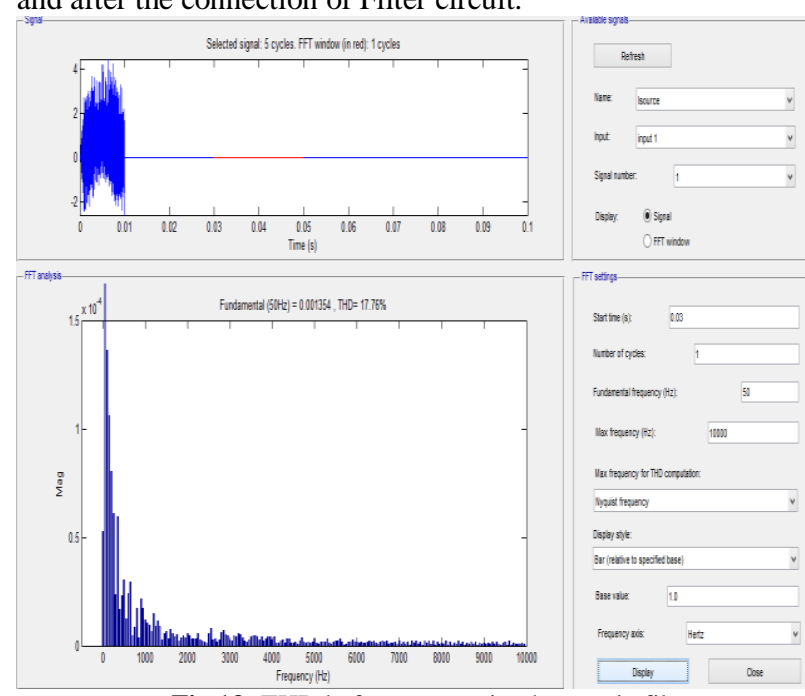

Fig.13: THD before connecting harmonic filter

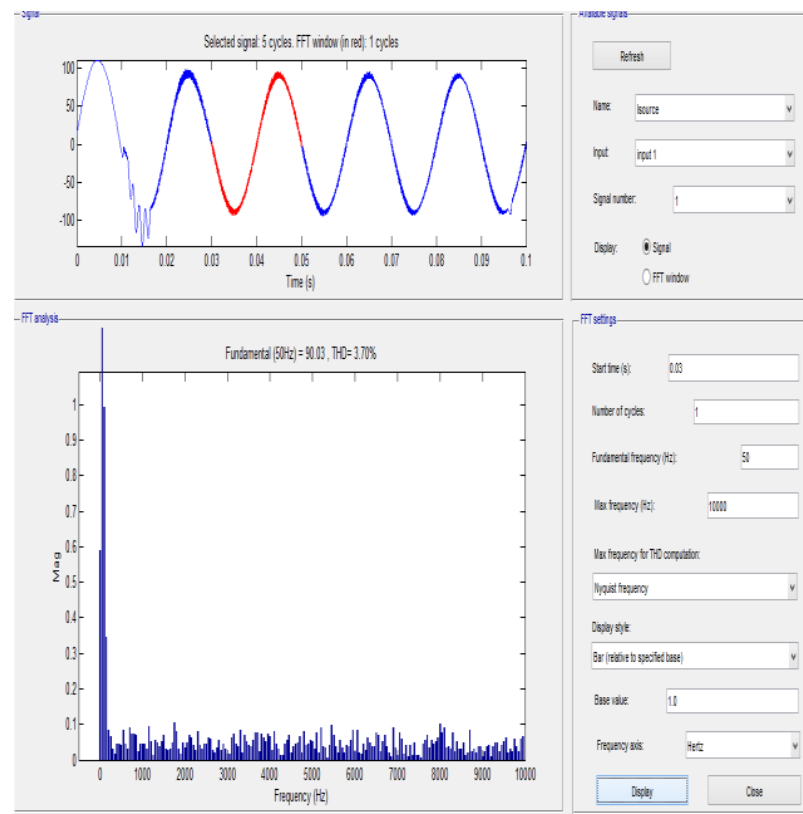

Fig.14: THD after connecting harmonic filter

\section{Conclusion}

The proposed system harmonic elimination using shunt active filter simulated using MATLAB simulation. The results prove that the proposed system implemented in the distribution system eliminates the harmonics effectively. The THD analysis for the current without the active filter is producing an output of $17.17 \%$. The implemented controller makes the THD value for the current to $3.7 \%$. The harmonics elimination percentage is around 5\%. The proposed system achieves the goal. The proposed system can be tested and verified using Microcontroller in real time implementation. The Artificial techniques like neural network, Fuzzy logic controller can be implemented to eliminate the harmonics.

\section{References}

[1] S.L.Gbadamosi, A.O.Melodi "Harmonic Distortion from Induction Furnace Loads In a Steel Production Plant", Network and Complex Systems, Vol.3, No.10, (2013).

[2] S.Ravi, C.Sujitha, Bakary Diarra, P.Sukumar, "Design and development of fuzzy system based unified power quality conditioner for harmonic elimination", Indian Journal of Science and Technology, Vol.10, No.6, (2017), pp. 1-5.

[3] Ying-Tung Hsiao "Design Of Filters For Reducing Harmonic Distortion And Correcting Power Factor In Industrial Distribution Systems" Tamkang Journal of Science and Engineering, Vol. 4, No. 3, pp. 193-199, (2001).

[4] S.Ravi, V.Mezhuyev, K I Annapoorani, P.Sukumar, "Design and implementation of a microcontroller based buck boost converter as a smooth starter for permanent magnet motor" Indonesian Journal of Electrical Engineering and Computer Science, Vol.1, No.3, (2016), pp.566-574.

[5] T. Nageswara Prasad, V. Chandra Jagan Mohan, V.C. Veera Reddy "Harmonic Reduction in Hybrid Filters for Power Quality Improvement in Distribution Systems", Journal of Theoretical and Applied Information Technology, Vol. 35, No.1, (2012).

[6] S.Ravi, G.Rajpriya, V.Kumarakrishnan, "Design and Development of Microcontroller Based Selective Harmonic Elimination Technique for Three Phase Voltage Source Inverter" International Journal of Applied Engineering Research, Vol.10, No.13, (2015), pp.11562-11578. 